\title{
The Influence of Residents' Opinions on the Redesign of Urban Underground Streets: A Case Study from Diyi Underground Street
}

\author{
Pei Zhang \\ GSST, Kumamoto University, Kumamoto, Japan \\ Email: coocoobar@foxmail.com
}

How to cite this paper: Zhang, P. (2018) The Influence of Residents' Opinions on the Redesign of Urban Underground Streets: A Case Study from Diyi Underground Street. Journal of Building Construction and Planning Research, 6, 215-233.

https://doi.org/10.4236/jbcpr.2018.64015

Received: October 19, 2018

Accepted: November 11, 2018

Published: November 14, 2018

Copyright $\odot 2018$ by author and Scientific Research Publishing Inc. This work is licensed under the Creative Commons Attribution International License (CC BY 4.0).

http://creativecommons.org/licenses/by/4.0/

\begin{abstract}
The rapid development of urbanization and rapid growth of urban population have brought about various urban problems, and the development of cities to the ground and underground has become an inevitable choice. Underground street is a kind of underground space types, and it is also an important urban recreational resources and tourism resources. The evaluation of underground street users, especially the residents and tourists, has important reference value for the recreational resources' redevelopment of underground street. Firstly, this paper reviews the relevant research literature on underground street and Post-Occupancy Evaluation theory, then chooses Diyi Underground Street, Chengdu, China, as the research object, and conducts a questionnaire survey and in-depth interviews on residents' shopping intention from five dimensions of underground street environment, decoration, commercial form, public facilities and other aspects. Finally, the survey data are analyzed quantitatively. The results show that some influence factors such as air quality, daylighting, decoration style etc. greatly affect the willingness of residents to enter the street. Therefore, residents' recreational experience should be emphasized during the underground street re-planning according to the above factors.
\end{abstract}

\section{Keywords}

Visitors' Opinion, Resident, Post-Occupancy Evaluation, Redesign, Urban Underground Space, Recreation, Urban Underground Street

\section{Introduction}

Since 1950, the world's urban population has increased rapidly, from 751 million to 4.2 billion in 2018 [1]. Rapid urbanization will inevitably bring a series of 
problems, such as excessive population agglomeration, traffic congestion, land shortage, ecological environment deterioration and so on, so urban developing upward and downward is an inevitable choice. With the development of the city, there has been a competition of Skyscraper construction. However, skyscrapers have brought about many problems, such as difficult construction, high construction cost, high use cost, high energy consumption, poor ventilation effect, difficult rescue and so on, which have been constantly criticized and questioned. Therefore, more and more attention has been paid to the underground space development.

There are many types of underground public spaces, and underground streets are one of them. The development of underground streets is becoming more and more mature after nearly 100 years of development. From channel to street, from line street to street network, people have accumulated rich experience in the long history. In the past 20 years, urban underground public space has been developing towards the integration of ground and underground space. People begin to combine underground public space construction with large-scale urban renewal and development planning, and further with the development of transportation hub areas. Therefore, the underground street has gradually developed from the original traffic, civil air defense and other municipal and technical space into a city recreational public space which can accommodate more commercial, tourism, leisure, entertainment, cultural and other activities. Therefore, the underground street has also become an important recreational resource and tourism resource.

Affected by the global upsurge of underground space development, the Chinese government clearly pointed out in 2006 that the rational development and utilization of underground space is an important development direction of Chinese cities in the future. In the same year, the Chinese government promulgated the Measures for the Compilation of Urban Planning, formally incorporating underground space development into the urban planning system. At the same time, as Chinese subway development entered the high-speed development period, the development and utilization of urban underground space had been promoted more rapidly. However, due to the lack of scientific planning, design and rational use, many underground space resources have been wasted or not yet effectively developed. Diyi Underground Street, in Chengdu, China, is a typical example. This street was first built during the Cold War for war defense. Since the 1980s, the Chengdu Municipal Government has begun to transform the air raid shelter in this area into an underground commercial street, but it didn't succeed. In 2009, an enterprise took it over and spent a lot of money to redecorate the street and renamed it as Diyi Underground Street. It was supposed that the street will flourish forever. However, it seems destined to fail from opening. In sharp contrast to the flourishing and crowded public space on the ground, Diyi Underground Street has a short period of lively opening, most of the time the doors and courtyards are deserted, and few people are seen. 
The author has made field research on Nagoya, Japan, which is very similar to Chengdu. The underground street in Nagoya is about $1,700,000 \mathrm{~m}^{2}$ in size only next to Tokyo and Osaka. This underground street is a very busy business district with a large number of shops and well-known department stores, such as Mitsukoshi and Matsuzaka. It is cheap and beautiful, a wide range of goods, but not easy to get lost, and this is the most distinctive Nagoya recreational space unaffected by climate conditions. It does not only attract city residents but also attracts tourists. The underground street is a major touristic destination for foreign tourists, and its status is no less than that of Nagoya's representative attractions.

So, what is the reason that Diyi Underground Street cannot be as prosperous as Japan's metropolitan underground streets, why do residents and tourists not want to visit the street? Even if it's windy and rainy or hot summer or cold winter, why isn't there much popularity along the street? This aroused the author's strong research interest. From the point of view of the users, especially the residents, it is the main motivation and purpose of this paper to study the deep reasons why they do not go to the street, so as to provide solutions for the re-development and reuse of recreational space resources in similar underground streets.

\section{Literature Review}

\subsection{Underground Street Related Research}

Underground space is a hot research topic in the field of urban planning and geotechnical engineering. There are some specialized journals, such as Underground Space and Tunnelling and Underground Space Technology in the world. Even in China, there is also a specialized Journal: Chinese Journal of Underground Space and Engineering journal. However, underground space is also a very big topic. According to the existing research literature, there are few papers on underground streets, although underground streets have been well developed in many countries or regions for nearly 100 years. Comparatively speaking, Japan attaches great importance to the related research of underground streets. The term "underground street" originally derives from the literal translation of Japanese and can be interpreted literally as "street underground". However, the English expression of underground street in Japanese academia is underground town. From its meaning, Japan expects the underground street to become the "town" of underground life expansion from the beginning, not a simple concept of "street".

Underground Space Research Committee (UBS), a group belongs to Japanese Society of Civil Engineering, is chaired by prominent professors from Kyoto University and Nagoya University. In 1995, the Committee publicly recruited four sub-committees: the Planning Committee, the Environmental Disaster Prevention Committee, the Psychological Committee and the Maintenance and Management Committee. Since 1996, the four sub-committees have been work- 
ing on the following topics: efficiency of underground space utilization, economic evaluation, maintenance status of underground structures, the role of urban underground space in disaster prevention, and the psychology of underground space movement [2]. Unfortunately, most of the above research literature written in Japanese, so researchers might not be aware of them.

At present, the study of underground street in academia is mostly discussed in the following three directions: the first is from the perspective of civil engineering to explore the investigation, structure, materials, engineering design, engineering survey, construction organization and engineering management of underground street; the second is from the perspective of urban planning to explore the development of underground street; the third direction is to discuss the daily management of underground street, such as propaganda, operation, safety and disaster prevention, from the angle of operation and management of underground street. There are two points in common in these three directions: first, they are confined to the discussion by the developers, designers and managers of the underground street itself, too much of which is injected into the thinking of the developers, designers and managers, less involving the users, that is, the customer groups of the underground street, and there is a disconnection between the first three and users, after all the development and utilization of the street users must be residents and tourists. The second is to ignore the recreational development value of underground streets or the value of tourism development. As a kind of public space resources, the recreational value of underground street will develop with the continuous development of urban tourism. The development and utilization value of this kind of resources is no less than that of urban tourism resources. Therefore, the development and utilization of underground streets must pay attention to the recreational experience of residents and tourists. This is of great significance to the development of underground streets in large cities and the establishment of a comprehensive theoretical system of underground recreational space.

\subsection{Research Progress of Post-Occupancy Evaluation}

Post-Occupancy Evaluation, or POE for short, is a special indicator for evaluating buildings and related environments after they have been built and used for a certain period. It is concerned with the actual use of buildings and related environments and the users' opinions. The POE principle is to collect feedback user information by comparing the expected purpose of building and planning with the actual use, so as to provide reliable objective basis for the future planning, design, architectural decision-making of similar buildings and environments.

The name POE is said to be derived from the occupancy permit issued under the Building Code and Regulations (Bechtel 1980) when a building is completed, inspected, considered safe [3]. The theoretical study of POE began in 1960s in Europe and the United States. In 1966, Osmond, an American, conducted a post-use evaluation of special buildings such as prisons and psychiatric hospitals 
(Osmond, 1966) [4]. By investigating these special buildings, the researchers assessed the impact of the buildings on the mental health and safety of their users and suggested improvements in similar buildings.

From the late 1960s to the 1970s, several important related works were published in developed countries, such as: The Behavioral Basis of Design (Robert Sommer, 1969), Tight Spaces: Hard Architecture and How to Humanize It (Robert Sommer, 1974), The Hidden Dimension (Edward T. Hall, 1966), The Fourth Dimension in Architecture: The Impact of Building on Man's Behavior (Edward T. Hall, 1975). In the late 1970s, specialized magazines such as Environment and Behavior, The Journal of Environmental Psychology, Architecture and Progressive Architecture appeared. By 1980s, in developed countries, the government and construction department had classified POE as a routine activity. POE is also listed as a teaching course by some architectural colleges.

Wolfgang F.E. Preiser, an important figure in the field of POE, developed post-use evaluation methodology, making post-use evaluation one of the required majors of the American Council of Architects, and created the International Association for Building Performance Assessment, which greatly promoted the development of POE. Post-Occupancy Evaluation (1988), a representative work of Wolfgang F. E. Preiser, Harvey Z. Rabinow ITZ and Edward T. Whit, is a classic work on POE research in the world [5]. In Post-Occupancy Evaluation, Wolfgang F. E. Preiser classifies POEs into three categories according to the depth of evaluation of buildings ${ }^{1}$. Wolfgang F. E. Preiser, in his Architectural Performance Assessment, said that "In the words of the Royal Society of Architects, the greatest improvement in consumer focus is the systematization of feedback and the establishment of post-use evaluations" [6].

In recent years, the field of POE has expanded from academic field to professional field. Today, POE is offered as part of a specialized service (Slavic, 1982) by a growing number of consultants, as well as selected progressive construction and planning companies. Therefore, POE has now become an established discipline, almost affecting the various stages of the construction process [7].

As a public building and recreational resource, it is very necessary for underground streets to carry out POE. The users of underground street are mainly urban residents and tourists, and their perception is very important for the development of underground street. Especially for underground streets which have been developed but not successful, POE has important reference value.

\section{Methodologies}

\subsection{Introduction to the Research Case}

Diyi Underground Street (Figure 1), Chengdu, China, started Yuhe River civil

${ }^{1}$ The three categories includes: 1 ) declarative POEs, which directly describe the advantages and disadvantages of the target building, and collect relevant information through documents, Walk-through Evaluation, questionnaires and interviews; 2) investigative POE, which can be initiated when declarative POE finds special problems and needs further study; 3) Diagnostic POE, the most thorough and comprehensive POE, lasts the longest for several months to a year, or even longer. 


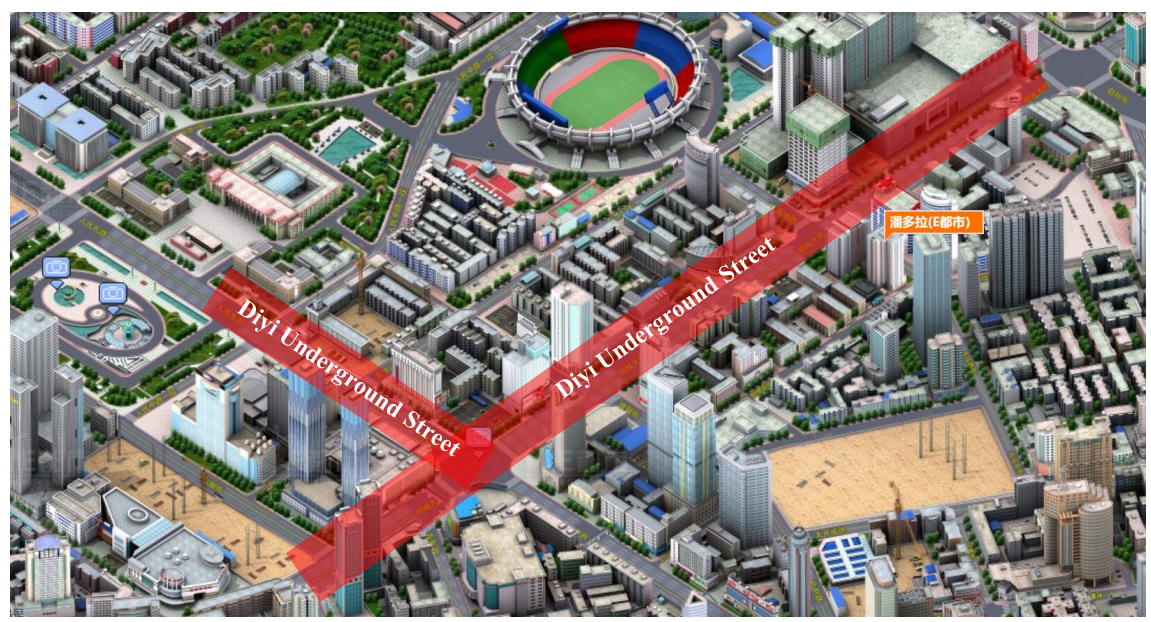

Figure 1. Location of Diyi underground street in Chengdu.

air defense project in September 1971. In August 1981, the civil air defense project was funded by the government to create an underground street and renamed Yuhe Youth Underground Mall. In the 1990s, the mall was redecorated and renamed Tianzuo Mall again. The goal of building a first-class underground street in China was put forward. It is 2.1 kilometers in length, 10 meters in width, 2.65 meters in height and 21,000 square meters in use area. When business is booming, mall managers have to restrict people to enter the underground streets at 3 p.m. But ten years later, there was a business crisis in the street. In 2009, a well-known private enterprise in China contracted for 40 years the right to develop Tianzuo Mall. In December 23, 2011, the underground street was renovated and formally opened. This time the underground street composed of two sections, north of Shuncheng Avenue from Guangzhou Department Store to Yanshikou Business District, 1216 meters in length, west of Dongyu Street and Tianfu Square, the largest subway transfer station in Chengdu, connected with the winter solstice Yanshikou Business District, 425 meters in length, the overall area of the project is 90,500 square meters. The overall design of the underground street is two stories, with more than 50 entrances. As a link between Yanshikou, Chunxi Road and Mumashi, Diyi Underground Street became another flagship work of Diyi brand in Western China. However, at present, the street has also been closed to the public. The residents and tourists are rarely seen in the underground street.

\subsection{Research Methods}

\subsubsection{Questionnaire Survey}

First, a questionnaire was designed according to the need of research. The questionnaire is divided into three parts: the first part, the respondents' demographic characteristics, including the basic information of the respondents' gender, age, occupation, income, educational background, marital status, etc. The second part, the influencing factors of underground street users, is divided into five dimensions: environment, decoration, public facilities, commercial form and other di- 
mensions; the third part, the influencing factors of underground street users and the public wish to visit the underground street. A total of 52 items were designed in the questionnaire. All items except the first and third parts were measured by Likert Scale. The scores of each item indicate that the respondents' recognition of the indicators, and the scores from 5 to 1 indicate that the respondents' recognition gradually decreases. Among them, the score on the willingness of residents to enter underground is $5=$ very willing, 4 is more willing, 3 = general, $2=$ relatively unwilling, 1 = very unwilling; the score on the influencing factors of residents to go underground is $5=$ very important, $4=$ more important, $3=\mathrm{im}$ portant, 2 = not important, 1 = very unimportant. After the preliminary design of the questionnaire, the author obtained the guidance and suggestions of the peer experts and revised and supplemented the evaluation factors of some items. Then, 50 teachers and students of a university were selected for the pre-test of the questionnaire, which was revised and perfected again, and a formal questionnaire was formed.

\subsubsection{0n-Site Interviews}

The on-site interview method refers to the fact that the interviewer has a face-to-face conversation with the user to understand the user's psychological feelings and actual needs. From the standardization degree of interview, it can be divided into structured interview, semi-structured interview and non-structured interview. Structural interviews need to prepare questions and possible responses in advance, and then proceed to the next step according to the responses; semi-structured interviews refer to the combination of questionnaires in interviews, as an in-depth supplement to the questionnaire survey; non-structured interviews refer to informal, open, high degree of freedom of impromptu communication. In this paper, semi structured interviews are conducted to conduct in-depth interviews with some of the respondents.

\subsection{Data Sources}

Users of urban underground streets should include residents and tourists. Limited to time and energy, this paper will focus on investigating the residents. In the stage of formal investigation and interview, the author organized some graduate students to conduct random questionnaires and interviews on the streets of Chengdu residents at 24 entrances and exits of Diyi Underground Street for 5 times from May to August 2018. In the process of investigation, except for the necessary explanation of underground street, the author always does not give any guidance to the test items, to investigate the authenticity and reliability of the data. A total of 220 questionnaires were sent out and 220 questionnaires were collected, of which 201 were valid, with an effective rate of $95.7 \%$. The data were first entered SPSS 22.0 for descriptive statistical analysis, reliability and validity tests, and then analyzed by AMOS $22.0^{2}$.

${ }^{2} \mathrm{AMOS}$ is a structural equation model analysis software, mainly for confirmatory factor analysis. 


\section{Results}

\subsection{Basic Information Analysis of Survey Samples}

In this survey, women are more than men, 18 - 35 years old accounts for $86.1 \%$ of the total sample. Civil servants and enterprise employees are the majority of the profession. College (undergraduate) is the main education and fewer respondents with other academic qualifications. Persons with a monthly income of $3500-7500 \mathrm{RMB}^{3}$ account for $77.2 \%$ of the total sample and more than $60 \%$ are married. Details are shown in Table 1.

Table 1. Basic information analysis of survey samples $(\mathrm{N}=201)$.

\begin{tabular}{|c|c|c|c|}
\hline Attributes & Classification & Frequency & Percentage (\%) \\
\hline \multirow{5}{*}{ Age } & $18-25$ years & 142 & 70.6 \\
\hline & $26-35$ years & 31 & 15.4 \\
\hline & $36-45$ years & 17 & 8.5 \\
\hline & 46 - 60 years & 7 & 3.5 \\
\hline & Over 60 years & 4 & 2.0 \\
\hline \multirow{2}{*}{ Sex } & Male & 86 & 42.8 \\
\hline & Female & 115 & 57.2 \\
\hline \multirow{2}{*}{ Marital status } & Married & 74 & 36.8 \\
\hline & Unmarried & 127 & 63.2 \\
\hline \multirow{4}{*}{ Education } & High school & 9 & 4.5 \\
\hline & Undergraduate & 15 & 7.5 \\
\hline & Master & 153 & 76.1 \\
\hline & Doctor & 24 & 11.9 \\
\hline \multirow{6}{*}{ Occupation } & Civil servant & 132 & 65.7 \\
\hline & Enterprise staff & 46 & 22.9 \\
\hline & Freelance & 11 & 5.5 \\
\hline & Self-employer & 8 & 4.0 \\
\hline & Student & 3 & 1.5 \\
\hline & Others & 1 & 0.4 \\
\hline \multirow{6}{*}{ Monthly income } & Less than $2000 \mathrm{RMB}$ & 2 & 1.0 \\
\hline & $2001-3500 \mathrm{RMB}$ & 21 & 10.4 \\
\hline & $3501-5000 \mathrm{RMB}$ & 79 & 39.3 \\
\hline & $5001-7500 \mathrm{RMB}$ & 56 & 27.9 \\
\hline & $7501-10000 \mathrm{RMB}$ & 31 & 15.4 \\
\hline & More than $10000 \mathrm{RMB}$ & 12 & 6.0 \\
\hline
\end{tabular}

${ }^{3}$ According to the latest exchange rate, 1 dollar is equivalent to $6.9 \mathrm{RMB}$. 
Reliability is used to analyze the consistency level of the results obtained by a measurement method and to evaluate the reliability of the scale and the measurement method by using this consistency as an indicator. Among them, the internal consistency reliability is mainly tested by Krenbach alpha coefficient to test the consistency of the respondents' answers to all items in the same scale. The reliability coefficient of the scale is above 0.6 , indicating that the internal consistency of the scale is acceptable. The internal consistency of the scale is better between 0.7 and 0.8 , and better than 0.8 . Using SPSS22.0 to test the reliability of the scale, we can see that the Klumbach alpha coefficient $(\alpha)$ of the scale is 0.915 , greater than 0.8 , so we can infer that the reliability of the questionnaire is still good, the scale has a high internal consistency.

\subsection{Validity Analysis of Scale}

Validity is that the scale can accurately measure the degree of the variables to be measured, that is, the use of the questionnaire can measure the degree of the variables to be measured. Generally speaking, AMOS is used for confirmatory factor analysis, and model fitting index is used to test the structural validity of the scale. AMOS22.0 is used for confirmatory factor analysis of the questionnaire, and the fitting indices of each model are shown in Table 2.

According to the results of validity test of Table 2, the questionnaire has good construct validity. In conclusion, the scale has good reliability and validity, and can effectively measure the willingness of residents to enter the underground street.

\subsection{Factor Analysis}

Before performing factor analysis, KMO and Bartlett sphericity tests are needed. When the following two conditions are met at the same time: 1) KMO value, KMO value index results must be greater than 0.6 ; 2) Bartlett sphericity test results must reach a significant level (significance level is less than 0.05), indicating that the data suitable for factor analysis (Table 3).

From Table 3, KMO $=0.955>0.6$, and Bartlett sphericity test results reach a significant level (that is, the significance level is less than 0.001 ), indicating that the data is very suitable for factor analysis.

Table 2. Validity test of scale.

\begin{tabular}{cccccc}
\hline Fitting index & $\chi^{2} / \mathrm{df}$ & CFI & NFI & TLI & RMSEA \\
\hline Figure & 24.86 & 0.94 & 0.93 & 0.90 & 0.06 \\
\hline
\end{tabular}

Table 3. Test of KMO and Bartlett.

\begin{tabular}{lcc}
\hline \multicolumn{2}{c}{ Kaiser-Meyer-Olkin metric for sampling sufficiency } & 0.955 \\
& Approximate chi square & 10286.485 \\
Sphericity test of Bartlett & Df & 496 \\
& sig. & 0.000 \\
\hline
\end{tabular}


From the results of Table 4, we can see that the 48 items of the scale can extract 12 principal factors under the principle that the eigenvalue is greater than 1 . The cumulative variance contribution rate of the 12 principal factors is $89.26 \%>$ $60 \%$. It can be seen that the information extracted from the 12 principal factors is very large. At the same time, the explanatory value of the maximum common factor is $17.15 \%<40 \%$, indicating that there is no common method deviation. The rotational component matrix is shown in Table 5.

\subsection{Descriptive Analysis}

This study uses Likert Scale. The higher the score is, the less important the representative dimension is. The following table shows: in the environmental dimension, air quality and daylighting are considered to be the most important, with an average value of 1.18 , followed by ventilation and humidity, with an average value of 1.97 (Table 6). Therefore, in the view of investigators, air quality and lighting are very important in the environmental dimension.

From the following table, we can see that the underground street decoration style, decoration materials mean 1.18 , that is, the investigators believe that in decoration, these two are the first; followed by lighting decoration and public landscape, $M=2.75$; decoration technology, store decoration mean 2.80; in decoration this specific content, the investigators believe that wall decoration. It is not important, the mean is the largest, $\mathrm{M}=3.68$ (Table 7).

Table 4. Total variance explained.

\begin{tabular}{ccccccc}
\hline \multirow{2}{*}{ Components } & \multicolumn{3}{c}{ Initial eigenvalue } & \multicolumn{3}{c}{ Extracting sum of squares } \\
\cline { 2 - 7 } & Total & $\begin{array}{c}\text { \% of the } \\
\text { variance }\end{array}$ & $\begin{array}{c}\text { Cumulative } \\
\%\end{array}$ & Total & $\begin{array}{c}\text { \% of the } \\
\text { variance }\end{array}$ & $\begin{array}{c}\text { Cumulative } \\
\%\end{array}$ \\
\hline 1 & 8.232 & 17.150 & 17.150 & 8.232 & 17.150 & 17.150 \\
2 & 6.844 & 14.258 & 31.408 & 6.844 & 14.258 & 31.408 \\
3 & 5.200 & 10.834 & 42.242 & 5.200 & 10.834 & 42.242 \\
4 & 4.984 & 10.383 & 52.625 & 4.984 & 10.383 & 52.625 \\
5 & 4.191 & 8.732 & 61.357 & 4.191 & 8.732 & 61.357 \\
6 & 3.112 & 6.483 & 67.840 & 3.112 & 6.483 & 67.840 \\
7 & 2.383 & 4.965 & 72.805 & 2.383 & 4.965 & 72.805 \\
8 & 2.053 & 4.278 & 77.083 & 2.053 & 4.278 & 77.083 \\
9 & 1.947 & 4.057 & 81.140 & 1.947 & 4.057 & 81.140 \\
10 & 1.690 & 3.520 & 84.660 & 1.690 & 3.520 & 84.660 \\
11 & 1.177 & 2.452 & 87.112 & 1.177 & 2.452 & 87.112 \\
12 & 1.033 & 2.151 & 89.263 & 1.033 & 2.151 & 89.263 \\
13 & 0.959 & 1.998 & 91.261 & & & \\
14 & 0.913 & 1.903 & 93.164 & & & \\
\hline
\end{tabular}




\section{Continued}

\begin{tabular}{|c|c|c|c|}
\hline 15 & 0.783 & 1.632 & 94.795 \\
\hline 16 & 0.725 & 1.511 & 96.307 \\
\hline 17 & 0.645 & 1.344 & 97.650 \\
\hline 18 & 0.583 & 1.214 & 98.864 \\
\hline 19 & 0.435 & 0.907 & 99.771 \\
\hline 20 & 0.084 & 0.174 & 99.945 \\
\hline 21 & 0.027 & 0.055 & 100.000 \\
\hline 22 & $2.437 \mathrm{E}-16$ & $5.077 \mathrm{E}-16$ & 100.000 \\
\hline 23 & $1.502 \mathrm{E}-16$ & $3.129 \mathrm{E}-16$ & 100.000 \\
\hline 24 & $1.235 \mathrm{E}-16$ & $2.573 \mathrm{E}-16$ & 100.000 \\
\hline 25 & $9.176 \mathrm{E}-17$ & $1.912 \mathrm{E}-16$ & 100.000 \\
\hline 26 & $8.037 \mathrm{E}-17$ & $1.674 \mathrm{E}-16$ & 100.000 \\
\hline 27 & $5.103 \mathrm{E}-17$ & $1.063 \mathrm{E}-16$ & 100.000 \\
\hline 28 & $4.431 \mathrm{E}-17$ & $9.231 \mathrm{E}-17$ & 100.000 \\
\hline 29 & $2.885 \mathrm{E}-17$ & $6.010 \mathrm{E}-17$ & 100.000 \\
\hline 30 & $2.033 \mathrm{E}-17$ & $4.235 \mathrm{E}-17$ & 100.000 \\
\hline 31 & $1.053 \mathrm{E}-17$ & $2.194 \mathrm{E}-17$ & 100.000 \\
\hline 32 & $5.514 \mathrm{E}-18$ & $1.149 \mathrm{E}-17$ & 100.000 \\
\hline 33 & $1.888 \mathrm{E}-18$ & $3.933 \mathrm{E}-18$ & 100.000 \\
\hline 34 & $-8.598 \mathrm{E}-19$ & $-1.791 \mathrm{E}-18$ & 100.000 \\
\hline 35 & $-2.509 \mathrm{E}-18$ & $-5.226 \mathrm{E}-18$ & 100.000 \\
\hline 36 & $-1.151 \mathrm{E}-17$ & $-2.399 \mathrm{E}-17$ & 100.000 \\
\hline 37 & $-1.521 \mathrm{E}-17$ & $-3.168 \mathrm{E}-17$ & 100.000 \\
\hline 38 & $-2.272 \mathrm{E}-17$ & $-4.734 \mathrm{E}-17$ & 100.000 \\
\hline 39 & $-3.458 \mathrm{E}-17$ & $-7.204 \mathrm{E}-17$ & 100.000 \\
\hline 40 & $-4.933 \mathrm{E}-17$ & $-1.028 \mathrm{E}-16$ & 100.000 \\
\hline 41 & $-6.056 \mathrm{E}-17$ & $-1.262 \mathrm{E}-16$ & 100.000 \\
\hline 42 & $-7.782 \mathrm{E}-17$ & $-1.621 \mathrm{E}-16$ & 100.000 \\
\hline 43 & $-1.021 \mathrm{E}-16$ & $-2.126 \mathrm{E}-16$ & 100.000 \\
\hline 44 & $-1.231 \mathrm{E}-16$ & $-2.564 \mathrm{E}-16$ & 100.000 \\
\hline 45 & $-1.560 \mathrm{E}-16$ & $-3.250 \mathrm{E}-16$ & 100.000 \\
\hline 46 & $-2.267 \mathrm{E}-16$ & $-4.723 \mathrm{E}-16$ & 100.000 \\
\hline 47 & $-4.952 \mathrm{E}-16$ & $-1.032 \mathrm{E}-15$ & 100.000 \\
\hline 48 & $-5.601 \mathrm{E}-16$ & $-1.167 \mathrm{E}-15$ & 100.000 \\
\hline
\end{tabular}


Table 5. Factor load matrix.

\begin{tabular}{|c|c|c|c|c|c|c|c|c|c|c|c|c|}
\hline \multirow{2}{*}{ Items } & \multicolumn{12}{|c|}{ Components } \\
\hline & 1 & 2 & 3 & 4 & 5 & 6 & 7 & 8 & 9 & 10 & 11 & 12 \\
\hline Air quality & 0.742 & 0.546 & 0.069 & 0.026 & 0.021 & -0.058 & 0.027 & 0.059 & -0.124 & -0.081 & -0.057 & -0.077 \\
\hline Space & -0.121 & -0.012 & -0.071 & -0.141 & 0.055 & 0.124 & 0.152 & -0.107 & 0.007 & -0.124 & 0.698 & -0.207 \\
\hline Daylighting & 0.773 & 0.586 & 0.058 & -0.002 & 0.065 & -0.016 & 0.058 & -0.007 & 0.063 & -0.060 & 0.044 & 0.048 \\
\hline Sound & -0.210 & 0.238 & -0.366 & 0.804 & 0.324 & 0.107 & 0.020 & -0.001 & 0.024 & 0.005 & 0.010 & -0.027 \\
\hline Aeration & 0.036 & -0.126 & -0.002 & -0.375 & 0.899 & -0.068 & -0.109 & -0.017 & 0.009 & 0.072 & 0.007 & 0.015 \\
\hline Temperature & -0.045 & -0.094 & -0.040 & 0.085 & 0.059 & -0.380 & 0.502 & -0.074 & -0.266 & 0.216 & 0.136 & 0.256 \\
\hline Humidity & 0.036 & -0.126 & -0.002 & -0.375 & 0.899 & -0.068 & -0.109 & -0.017 & 0.009 & 0.072 & 0.007 & 0.015 \\
\hline Hygiene & -0.645 & 0.688 & 0.298 & -0.123 & 0.015 & -0.051 & 0.006 & -0.008 & 0.005 & 0.042 & 0.003 & -0.022 \\
\hline Decoration style & 0.773 & 0.586 & 0.058 & -0.002 & 0.065 & -0.016 & 0.058 & -0.007 & 0.063 & -0.060 & 0.044 & 0.048 \\
\hline Decorating material & 0.742 & 0.546 & 0.069 & 0.026 & 0.021 & -0.058 & 0.027 & 0.059 & -0.124 & -0.081 & -0.057 & -0.077 \\
\hline Decoration process & -0.645 & 0.688 & 0.298 & -0.123 & 0.015 & -0.051 & 0.006 & -0.008 & 0.005 & 0.042 & 0.003 & -0.022 \\
\hline Lighting decoration & -0.210 & 0.238 & -0.366 & 0.804 & 0.324 & 0.107 & 0.020 & -0.001 & 0.024 & 0.005 & 0.010 & -0.027 \\
\hline Floor covering & 0.086 & -0.288 & 0.649 & 0.294 & 0.098 & -0.185 & 0.195 & 0.159 & 0.501 & -0.032 & -0.036 & -0.098 \\
\hline Ceiling decoration & 0.029 & -0.207 & 0.250 & 0.092 & 0.132 & -0.236 & 0.211 & 0.106 & 0.318 & -0.101 & -0.080 & 0.008 \\
\hline Wall decoration & -0.068 & 0.135 & -0.063 & 0.071 & 0.036 & -0.077 & -0.076 & 0.020 & 0.000 & 0.200 & -0.662 & 0.314 \\
\hline Storefront decoration & -0.645 & 0.688 & 0.298 & -0.123 & 0.015 & -0.051 & 0.006 & -0.008 & 0.005 & 0.042 & 0.003 & -0.022 \\
\hline Public landscape & -0.210 & 0.238 & -0.366 & 0.804 & 0.324 & 0.107 & 0.020 & -0.001 & 0.024 & 0.005 & 0.010 & -0.027 \\
\hline Color matching & -0.645 & 0.688 & 0.298 & -0.123 & 0.015 & -0.051 & 0.006 & -0.008 & 0.005 & 0.042 & 0.003 & -0.022 \\
\hline Brand clothing store & 0.048 & -0.061 & 0.301 & -0.095 & 0.119 & 0.818 & 0.419 & -0.148 & -0.035 & 0.055 & -0.087 & -0.006 \\
\hline Accessories store & -0.210 & 0.238 & -0.366 & 0.804 & 0.324 & 0.107 & 0.020 & -0.001 & 0.024 & 0.005 & 0.010 & -0.027 \\
\hline Digital appliance store & 0.086 & -0.288 & 0.649 & 0.294 & 0.098 & -0.185 & 0.195 & 0.159 & 0.501 & -0.032 & -0.036 & -0.098 \\
\hline Book store & 0.152 & -0.189 & 0.753 & 0.423 & 0.042 & 0.002 & -0.270 & -0.101 & -0.282 & 0.054 & 0.085 & 0.099 \\
\hline Fast food restaurant & 0.773 & 0.586 & 0.058 & -0.002 & 0.065 & -0.016 & 0.058 & -0.007 & 0.063 & -0.060 & 0.044 & 0.048 \\
\hline Snack Bar & 0.742 & 0.546 & 0.069 & 0.026 & 0.021 & -0.058 & 0.027 & 0.059 & -0.124 & -0.081 & -0.057 & -0.077 \\
\hline Coffee shop/Teahouse & -0.645 & 0.688 & 0.298 & -0.123 & 0.015 & -0.051 & 0.006 & -0.008 & 0.005 & 0.042 & 0.003 & -0.022 \\
\hline Bar & 0.048 & -0.061 & 0.301 & -0.095 & 0.119 & 0.818 & 0.419 & -0.148 & -0.035 & 0.055 & -0.087 & -0.006 \\
\hline Drugstore & 0.152 & -0.189 & 0.753 & 0.423 & 0.042 & 0.002 & -0.270 & -0.101 & -0.282 & 0.054 & 0.085 & 0.099 \\
\hline Convenience store & 0.352 & 0.146 & -0.109 & 0.028 & -0.188 & 0.057 & -0.237 & -0.296 & 0.325 & 0.715 & 0.085 & -0.041 \\
\hline Household goods store & 0.036 & -0.126 & -0.002 & -0.375 & 0.899 & -0.068 & -0.109 & -0.017 & 0.009 & 0.072 & 0.007 & 0.015 \\
\hline
\end{tabular}




\section{Continued}

\begin{tabular}{|c|c|c|c|c|c|c|c|c|c|c|c|c|}
\hline Mother and baby shop & 0.089 & -0.232 & 0.711 & 0.406 & 0.016 & 0.016 & -0.265 & -0.093 & -0.323 & 0.039 & 0.067 & 0.098 \\
\hline Children's playground & 0.036 & -0.126 & -0.002 & -0.375 & 0.899 & -0.068 & -0.109 & -0.017 & 0.009 & 0.072 & 0.007 & 0.015 \\
\hline Beauty salon & 0.048 & -0.061 & 0.301 & -0.095 & 0.119 & 0.818 & 0.419 & -0.148 & -0.035 & 0.055 & -0.087 & -0.006 \\
\hline Ballroom/Kara OK Hall & 0.152 & -0.189 & 0.753 & 0.423 & 0.042 & 0.002 & -0.270 & -0.101 & -0.282 & 0.054 & 0.085 & 0.099 \\
\hline Cinema & 0.067 & -0.257 & 0.649 & 0.278 & 0.095 & -0.195 & 0.187 & 0.164 & 0.504 & -0.025 & -0.037 & -0.112 \\
\hline Toilet & 0.100 & 0.015 & 0.039 & 0.103 & -0.069 & -0.032 & -0.101 & -0.002 & -0.236 & -0.197 & -0.276 & -0.428 \\
\hline Bank ATM & -0.177 & 0.032 & -0.017 & 0.114 & 0.036 & 0.020 & 0.009 & 0.037 & 0.183 & -0.225 & 0.160 & 0.260 \\
\hline Rest table and chair & -0.040 & 0.157 & -0.062 & -0.037 & -0.012 & 0.069 & 0.101 & 0.075 & 0.199 & -0.191 & 0.137 & 0.668 \\
\hline $\begin{array}{l}\text { Communication } \\
\text { public facilities }\end{array}$ & 0.773 & 0.586 & 0.058 & -0.002 & 0.065 & -0.016 & 0.058 & -0.007 & 0.063 & -0.060 & 0.044 & 0.048 \\
\hline Elevator & 0.033 & -0.108 & -0.002 & 0.103 & 0.049 & -0.540 & 0.677 & -0.150 & -0.294 & 0.232 & -0.009 & -0.034 \\
\hline Guide sign & 0.773 & 0.586 & 0.058 & -0.002 & 0.065 & -0.016 & 0.058 & -0.007 & 0.063 & -0.060 & 0.044 & 0.048 \\
\hline Connect with subway & 0.352 & 0.146 & -0.109 & 0.028 & -0.188 & 0.057 & -0.237 & -0.296 & 0.325 & 0.715 & 0.085 & -0.041 \\
\hline Connect with bus stop & 0.151 & -0.004 & 0.174 & -0.129 & 0.476 & -0.070 & -0.112 & -0.027 & -0.158 & -0.053 & -0.052 & -0.124 \\
\hline $\begin{array}{l}\text { Connect with } \\
\text { department sore }\end{array}$ & 0.062 & 0.017 & 0.016 & -0.014 & -0.003 & 0.187 & 0.034 & 0.895 & -0.180 & 0.336 & 0.089 & -0.004 \\
\hline $\begin{array}{l}\text { Connect with office } \\
\text { building }\end{array}$ & -0.645 & 0.688 & 0.298 & -0.123 & 0.015 & -0.051 & 0.006 & -0.008 & 0.005 & 0.042 & 0.003 & -0.022 \\
\hline $\begin{array}{l}\text { Connect with } \\
\text { parking lots }\end{array}$ & 0.033 & -0.108 & -0.002 & 0.103 & 0.049 & -0.540 & 0.677 & -0.150 & -0.294 & 0.232 & -0.009 & -0.034 \\
\hline Theatrical performance & -0.210 & 0.238 & -0.366 & 0.804 & 0.324 & 0.107 & 0.020 & -0.001 & 0.024 & 0.005 & 0.010 & -0.027 \\
\hline $\begin{array}{c}\text { Commercial } \\
\text { promotion activities }\end{array}$ & -0.645 & 0.688 & 0.298 & -0.123 & 0.015 & -0.051 & 0.006 & -0.008 & 0.005 & 0.042 & 0.003 & -0.022 \\
\hline Security & 0.062 & 0.017 & 0.016 & -0.014 & -0.003 & 0.187 & 0.034 & 0.895 & -0.180 & 0.336 & 0.089 & -0.004 \\
\hline
\end{tabular}

Table 6. Descriptive analysis of environmental dimensions.

\begin{tabular}{|c|c|c|c|c|c|c|}
\hline Dimension & Items & $\mathrm{N}$ & Minimum & Maximum & Mean & Standard deviation \\
\hline \multirow{8}{*}{$\begin{array}{c}\text { Environment } \\
(\mathrm{M}=2.02)\end{array}$} & Air quality & 201 & 1 & 3 & 1.08 & 0.433 \\
\hline & Space & 201 & 1 & 4 & 2.18 & 0.521 \\
\hline & Daylighting & 201 & 1 & 3 & 1.28 & 0.448 \\
\hline & Sound & 201 & 1 & 5 & 2.75 & 0.740 \\
\hline & Aeration & 201 & 1 & 5 & 1.97 & 0.666 \\
\hline & Temperature & 201 & 1 & 5 & 2.17 & 0.561 \\
\hline & Humidity & 201 & 1 & 5 & 1.97 & 0.666 \\
\hline & Hygiene & 201 & 1 & 5 & 2.80 & 0.707 \\
\hline
\end{tabular}


Table 7. Descriptive analysis of decorative dimensions.

\begin{tabular}{ccccccc}
\hline Dimension & Items & N & Minimum & Maximum & Mean & Standard deviation \\
\hline & Decoration style & 201 & 1 & 3 & 1.18 & 0.448 \\
& Decorating material & 201 & 1 & 3 & 1.21 & 0.433 \\
& Decoration process & 201 & 1 & 5 & 2.80 & 0.707 \\
& Lighting decoration & 201 & 1 & 5 & 2.75 & 0.740 \\
Decoration & Floor covering & 201 & 1 & 5 & 3.61 & 0.767 \\
$(\mathrm{M}=2.72)$ & Ceiling decoration & 201 & 1 & 5 & 3.57 & 0.834 \\
& Wall decoration & 201 & 1 & 5 & 3.68 & 0.748 \\
& Storefront decoration & 201 & 1 & 5 & 2.80 & 0.707 \\
& Public landscape & 200 & 1 & 5 & 2.75 & 0.742 \\
\hline
\end{tabular}

There are a variety of stores in the commercial form dimension. From the following table, the smallest average is fast-food and snack shops, with an average of 1.18, which means that the two are very important in the underground streets, followed by small supermarkets, with an average of 1.56, and then more important are household goods and children's paradise, less important are brand clothing, bars and beauty salons. The mean is the highest (Table 8).

In the following table, the average value of public toilets is 1.53, bank ATM is 4.03 , rest tables and chairs are 1.32, communication facilities are 1.66, elevators are 2.41, and guide signs are 2.06 (Table 9). As can be seen from the above average, the most important thing is the rest of the table and chair, followed by public toilets, communications facilities, guide signs, elevators, the least important is the bank ATM, which is now more convenient mobile phone payment related, now convenient mobile phone payment, online operation, so that investigators think that bank ATM phone is not very important.

Except the above four dimensions are referred to in this article, the left is named "other dimensions". Among the following mean values, public security, and connect with subway are worth the highest score, $M=1.37$ (Table 10), indicating that respondents think highly of traffic convenience. The higher mean value is connected with commercial promotion activities, commercial promotions, indicating that respondents do not attach great importance to these two items.

When we told the respondents that if the government adopted their opinions in the future and redesigned Diyi Underground Street, the respondents expressed their willingness to continue visiting the street in the future, with an average of 1.43 and a mean of 2.13 to recommend their friends (Table 11). Therefore, the respondents said they would not like to visit the street later if it is not reformed.

As shown in Figure 2, the first ten items (factors) worth dividing into the lowest are air quality $(M=1.08)$, decoration style $(M=1.18)$, fast food $(M=1.18)$, 
Table 8. Descriptive analysis of commercial form dimensions.

\begin{tabular}{|c|c|c|c|c|c|c|}
\hline Dimension & Items & $\mathrm{N}$ & Minimum & Maximum & Mean & Standard deviation \\
\hline \multirow{16}{*}{$\begin{array}{l}\text { Commercial form } \\
\qquad(\mathrm{M}=3.14)\end{array}$} & Brand clothing store & 201 & 2 & 5 & 4.30 & 0.775 \\
\hline & Accessories store & 201 & 1 & 5 & 2.75 & 0.740 \\
\hline & Digital appliance store & 201 & 1 & 5 & 3.61 & 0.767 \\
\hline & Book store & 201 & 1 & 5 & 4.21 & 0.909 \\
\hline & Fast food restaurant & 201 & 1 & 3 & 1.18 & 0.448 \\
\hline & Snack bar & 201 & 1 & 3 & 1.20 & 0.433 \\
\hline & Coffee shop/teahouse & 201 & 1 & 5 & 2.80 & 0.707 \\
\hline & Bar & 201 & 2 & 5 & 4.30 & 0.775 \\
\hline & Drugstore & 201 & 1 & 5 & 4.21 & 0.909 \\
\hline & Convenience store & 201 & 1 & 5 & 1.56 & 0.994 \\
\hline & Household goods store & 201 & 1 & 5 & 1.97 & 0.666 \\
\hline & Mother and baby shop & 201 & 1 & 5 & 4.20 & 0.933 \\
\hline & Children's playground & 201 & 1 & 5 & 1.97 & 0.666 \\
\hline & Beauty salon & 201 & 2 & 5 & 4.30 & 0.775 \\
\hline & Ballroom/Kara OK Hall & 201 & 1 & 5 & 4.21 & 0.909 \\
\hline & Cinema & 201 & 1 & 5 & 3.61 & 0.761 \\
\hline
\end{tabular}

Table 9. Descriptive analysis of public facilities dimensions.

\begin{tabular}{ccccccc}
\hline Dimension & Items & N & Minimum & Maximum & Mean & Standard deviation \\
\hline & Toilet & 201 & 1 & 5 & 1.53 & 0.954 \\
Bank ATM & 201 & 2 & 5 & 4.03 & 0.830 \\
Public facilities & Rest table and chair & 201 & 1 & 5 & 1.32 & 1.027 \\
$(\mathrm{M}=2.16)$ & Communication facilities & 201 & 1 & 3 & 1.66 & 0.448 \\
& Elevator & 201 & 1 & 5 & 2.41 & 0.845 \\
\hline
\end{tabular}

Table 10. Descriptive analysis of other dimensions.

\begin{tabular}{ccccccc}
\hline Dimension & Items & $\mathrm{N}$ & Minimum & Maximum & Mean & Standard deviation \\
\hline & Connect with subway & 201 & 1 & 5 & 1.37 & 0.994 \\
& Connect with bus stop & 201 & 1 & 5 & 1.56 & 1.167 \\
& Connect with department sore & 201 & 1 & 5 & 2.41 & 0.791 \\
Other & Connect with office building & 201 & 1 & 5 & 2.80 & 0.707 \\
$(\mathrm{M}=2.36)$ & Connect with parking lots & 201 & 1 & 5 & 2.75 & 0.845 \\
& Theatrical performance & 201 & 1 & 5 & 2.96 & 0.740 \\
& Commercial promotion activities & 201 & 1 & 5 & 3.02 & 0.707 \\
& Public security & 201 & 1 & 5 & 2.04 & 0.791 \\
\hline
\end{tabular}


Table 11. Descriptive analysis of willingness to visit the underground street.

\begin{tabular}{|c|c|c|c|c|c|c|}
\hline & Items & $\mathrm{N}$ & Minimum & Maximum & Mean & Standard deviation \\
\hline \multirow{2}{*}{$\begin{array}{c}\text { Willingness } \\
(\mathrm{M}=1.78)\end{array}$} & $\begin{array}{l}\text { If it is not reformed, we will not go shopping on } \\
\text { the underground street again. }\end{array}$ & 201 & 1 & 5 & 1.43 & 0.834 \\
\hline & $\begin{array}{l}\text { If it is not reformed, we will not recommend } \\
\text { our friends to visit the underground street. }\end{array}$ & 201 & 1 & 5 & 2.13 & 1.083 \\
\hline
\end{tabular}

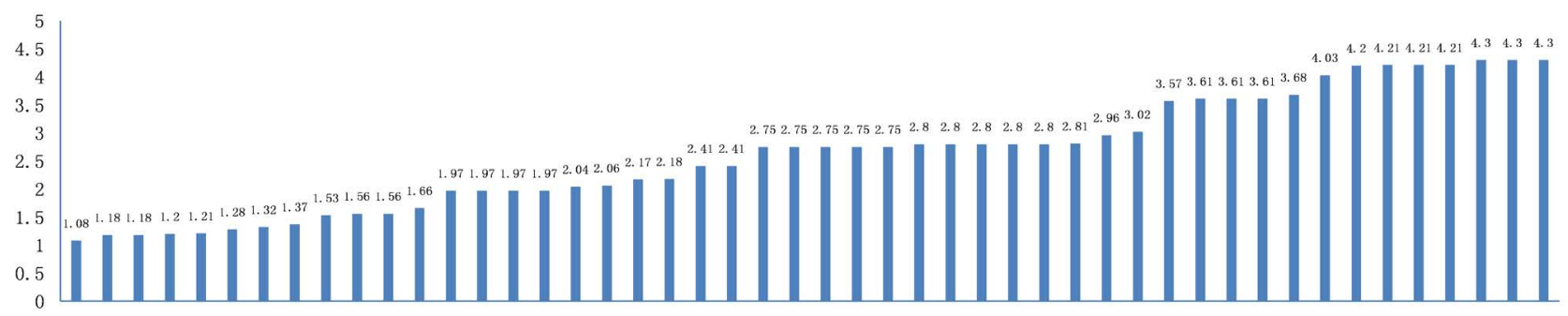

Figure 2. Importance of influencing factors.

snack bar $(M=1.20)$, decoration materials $(M=1.21)$, daylighting $(M=1.28)$, rest tables and chairs $(M=1.32)$, and connect with subway $(M=1.37)$, public toilets $(M=1.53)$, convenience store $(M=1.56)$, that is to say, in the opinion of the surveyors, the shopping mall is the most important of these ten items (Figure 2).

\section{Conclusions and Discussion}

\subsection{Redesign of Underground Street Environment}

Underground street environment is a very broad concept, and air quality is inherently closely related to lighting, ventilation, temperature and humidity. The most basic level of humanized design of underground street is to satisfy people's physiological needs and eliminate people's unhealthy psychology of underground street. Therefore, introducing natural light and lighting design is the main way to solve this problem. From the point of view of physiology and building thermal engineering, the most comfortable air temperature is about $22^{\circ} \mathrm{C}$. The thermal stability of underground street makes it easier to keep the internal temperature fluctuating in a small range of human comfort temperature points and less affected by external temperature changes. The temperature fluctuation in underground streets is affected by the number of people. According to physiological criteria, the most comfortable air relative humidity is about $65 \%$. The indoor relative humidity standard is $40 \%$ to $70 \%$. Air cleanliness is mainly manifested by whether there is enough oxygen in the air, carbon monoxide, carbon dioxide, floating dust and bacterial content in line with health standards. Standard clean air: $21.4 \%$ of oxygen and $0.04 \%$ of carbon dioxide. The composition of plank tonic dust in the air is more complex. When it exceeds a certain amount, it will make people feel uncomfortable. According to the results of questionnaires and interviews, Chengdu people generally believe that the air quality in Diyi Underground Street is bad, which is related to the poor ventila- 
tion and daylighting effect of underground street we see. Therefore, if we redevelop or redesign underground streets, we should pay attention to ventilation and daylighting, and effectively reduce noise and waste gas pollution and other environmental pollution, to create a green, ecological shopping and leisure environment for people.

\subsection{Redesign of Underground Street Decoration}

At present, China's underground street design, generally tend to use high-grade decoration materials, highlighting luxury quality. However, according to our investigation, visitors are not interested in the luxurious decoration of underground streets. Some of the respondents believe that high-grade marble has radiation, harmful to human body, and prone to slip. As a public recreation space, the underground street decoration style should be fashionable, young, lively, with fresh color, and the decoration materials used should be non-toxic and odorless. In relatively closed underground buildings, the smell of decoration materials will greatly affect people's willingness to shop. Therefore, the underground street should pay attention to greening, and pay attention to the use of environmental protection and energy saving materials.

As a part of the urban recreational space, the underground street represents the non-verbal cultural symbols, and its spatial form also contains certain meanings or symbols. It also exerts a subtle and profound influence on people's behavior and personality. Therefore, the design of underground street should also reflect the cultural characteristics of the city, cultural characteristics include cultural symbols and cultural concepts. The cultural characteristics of the underground street should be reflected through the city's architectural cultural symbols and urban cultural concepts. That is to say, the underground streets of every city should have their own style and personality. As for Diyi Underground Street, how this underground street reflects Chengdu's traditional culture and modern fashion culture is indeed a difficult problem.

\subsection{Redesign of Underground Street Commercial Form}

Underground street commercial form is the most important factor to attract customers, the main commercial forms are generally: clothing, shoes and hats, cosmetics, groceries, cultural goods, leisure food, catering, bookstores, supermarkets, cakes, coffee shops, electrical stores and so on. The unreasonable commercial form is a common problem in the construction of underground streets in China at present. It is mainly manifested in the singleness of commercial form, the high proportion of clothing and apparel, the insufficiency of catering services, life shopping, cultural entertainment and so on. This is not conducive to the comprehensive benefits of the underground street play, cannot adapt to the modern multi-level, diversified life consumption. Take Diyi Underground Street as an example, clothing sales are still the main commercial form of $46 \%$, catering, entertainment, service business proportion is very low, less than $10 \%$. 
Such unreasonable commercial form has caused the lack of vitality of underground streets and the reluctance of customers to stay. We know that the biggest consumption characteristics of underground street are immediacy and convenience. According to our survey, fast food restaurants, snack shops and small supermarkets which provide convenient shopping and catering services are more popular with people, and the three items account for more than $45 \%$. In addition, household goods stores and children's parks are a good commercial form for gathering popularity.

\subsection{Redesign of Underground Street Public Facilities}

The service object of the underground street is human. In modern times, it is not only a shopping place, but also a public place for people to relax, and communicate with others. Therefore, in the design of underground streets, of course, we should pay attention to the humanized demands, such as paving bricks on the underground streets, setting chairs and benches, and so on. Public facilities are the necessary factors to facilitate the consumption of underground streets. It fully embodies the concern for people. Although the idea of "people-oriented" is more and more accepted by people, there are some environmental facilities in the design of underground streets, but people's feedback and investigation of environmental facilities are still imperfect. In this case study, although some chairs, small tables and other rest facilities are arranged along Diyi Underground Street, the number is still insufficient. At the same time, due to the weak communication signal of underground streets, the lack of public facilities, people do not have enough rest space after a period of walking. When they are tired, they have to choose to leave. This greatly reduces the attraction of underground street space environment.

With the improvement of people's pursuit of individuality, underground streets must create a unique image and form a recognizable if they want to attract customers. For example, the use of underground street location in the special ground environment, or to create a specific customer group of personalized design themes, and so on, are effective measures to shape the recognition of underground streets. Moving line design, logo design, decorative decoration, etc., can enhance the identifiability.

\subsection{Redesign of Underground Street Other Content}

In City Image, Kevin Lynch summarizes the material elements that form people's city image into five aspects: path, region, boundary, node and symbol. We can extend the five elements of urban image to the use of underground street space and form the five elements of underground street space identifiability. Starting from the characteristics of the five elements and processing methods, we can improve the current situation of the underground street space form uniform and lack of identifiability. For example, in this case, Diyi Underground Street is not connected with the surrounding shopping malls, subway and bus stations, people 
have to find another entrance and exit in and out of this underground street, very inconvenient. Entering the underground street is also very easy to get lost. To change this situation, it can be realized through the design of internal and external environment in underground space. Through entrance and exterior design and interior space layout to create a clear layout, well-organized, simple and rich in changes in the spatial structure to enhance the sense of direction in the underground.

\section{Acknowledgements}

The author thanks Chengdu Planning and Design Consulting Co., Ltd and some graduate students for their help in the research process. Without their support, this research cannot be completed successfully.

\section{Conflicts of Interest}

The author declares no conflicts of interest regarding the publication of this paper.

\section{References}

[1] https://www.un.org/development/desa/publications/2018-revision-of-world-urbani zation-prospects.html

[2] Underground Space Research Committee of Japan Civil Society http://www.jsce-ousr.org/

[3] Bechtel, R. (1980) What Are Post-Occupancy Evaluations? A Layman's Guide to POE for Housing. Final Draft Report. Environmental Research and Development Foundation, Tucson, AZ.

[4] Osmond, H. (1996) Some Psychiatric Aspects of Design. In: Holland, L.B., Ed., Who Designs America? Doubleday, Garden City, NY, 85.

[5] Preiser, W.F.E., Rabinowitz, H.Z. and White, E.T. (1988) Post-Occupancy Evaluation. Van Mostrand Reinhold Co., New York.

[6] Wolfgang, F.E. (1989) Building Evaluation. Plenum Press, New York.

[7] Slavin, M. (1982) The New Art of Positive Criticism. Interiors. 